\title{
A Tiling Approach to Represent Subgrid Snow Variability in Coupled Land Surface-Atmosphere Models
}

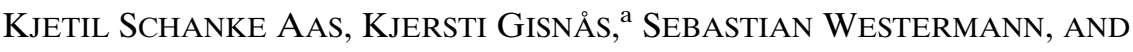 \\ TERJE KOREN BERNTSEN \\ Department of Geosciences, University of Oslo, Oslo, Norway
}

(Manuscript received 15 January 2016, in final form 4 October 2016)

\begin{abstract}
A mosaic approach to represent subgrid snow variation in a coupled atmosphere-land surface model (WRFNoah) is introduced and tested. Solid precipitation is scaled in 10 subgrid tiles based on precalculated snow distributions, giving a consistent, explicit representation of variable snow cover and snow depth on subgrid scales. The method is tested in the Weather Research and Forecasting (WRF) Model for southern Norway at $3-\mathrm{km}$ grid spacing, using the subgrid tiling for areas above the tree line. At a validation site in Finse, the modeled transition time from full snow cover to snow-free ground is increased from a few days with the default snow cover fraction formulation to more than 2 months with the tiling approach, which agrees with in situ observations from both digital camera images and surface temperature loggers. This in turn reduces a cold bias at this site by more than $2^{\circ} \mathrm{C}$ during the first half of July, with the noontime bias reduced from $-5^{\circ}$ to $-1^{\circ} \mathrm{C}$. The improved representation of subgrid snow variation also reduces a cold bias found in the reference simulation on regional scales by up to $0.8^{\circ} \mathrm{C}$ and increases surface energy fluxes (in particular the latent heat flux), and it resulted in up to $50 \%$ increase in monthly (June) precipitation in some of the most affected areas. By simulating individual soil properties for each tile, this approach also accounts for a number of secondary effects of uneven snow distribution resulting in different energy and moisture fluxes in different tiles also after the snow has disappeared.
\end{abstract}

\section{Introduction}

In mid- to high-latitude regions, the seasonal snow cover exerts an important influence on the energy transfer between the atmosphere and the land surface. With an albedo typically much higher than that of the surface below, the presence of snow reduces the amount of solar radiation absorbed by the surface. The very low thermal conductivity of snow makes it an efficient insulator between the atmosphere and the ground, further altering the surface temperature and energy balance (Zhang 2005). Snow is also an important energy sink during the melting season, preventing the surface temperature from rising above the melting point of ice. Finally, the storage of water in the snowpack from the accumulation season into the melting season may significantly change the availability of moisture for evapotranspiration and runoff. A realistic

\footnotetext{
${ }^{\text {a }}$ Current affiliation: Norwegian Geotechnical Institute, Oslo, Norway.
}

Corresponding authore-mail: Kjetil Schanke Aas, k.s.aas@ geo.uio.no representation of the snow cover and its related physical properties is therefore of key importance when simulating land surface processes and interactions with the atmosphere.

A major challenge when representing snow in land surface models (LSMs) is the nonuniform distribution of snow on the ground. A number of processes are responsible for variations in snow depth on different scales (Clark et al. 2011). Depending on the resolution of the model, some of these processes might be well represented, whereas others take place on too fine scales or are related to processes that are not accounted for in the model. In numerical weather prediction (NWP) models, redistribution of snow by wind is an example of the latter. Wind drift often dominates the local $(<1 \mathrm{~km})$ snow distribution pattern in nonforested mountainous regions, if the elevation differences on the subgrid scale are low (Clark et al. 2011). This results in an asymmetric distribution pattern of snow depths at subgrid scales.

To represent the subgrid snow distribution, many LSMs used in NWP models apply depletion curves to relate mean snow depth or mass to the snow cover fraction $(\mathrm{SCF})$. These vary in sophistication, from a 
simple linear relationship between snow water equivalent (SWE) and SCF (e.g., Sellers et al. 1996) to more advanced parameterizations accounting for different surface characteristics like surface roughness (e.g., Niu and Yang 2007) or subgrid topographic variance (e.g., Swenson and Lawrence 2012). In recent years more parameterizations also account for different SCF-SWE relationships for the accumulation and melt seasons (the hysteresis effect) either by using different functions (e.g., Swenson and Lawrence 2012; Samuelsson et al. 2015) or including snow density in the SCF formulation (e.g., Niu and Yang 2007; Dutra et al. 2010). LSMs also differ in how they apply the SCF: many models only use the SCF to estimate effective parameters like albedo or surface roughness used in a single surface energy balance (SEB). This can, however, lead to early snowmelt (Liston 2004), and some LSMs now simulate separate SEB for the snowcovered and snow-free fractions of each grid cell. In at least one regional climate model (RCA; Samuelsson et al. 2015) this also involves simulating different soil columns for the snow-covered and snow-free fraction.

Another approach for representing subgrid snow variations is to assume a probability distribution for snow at the end of the accumulation season. One such approach is described by Liston (2004), which assumes lognormal distributions with uniform melt rates. The SCF and mean snow depth can then be derived with analytical solutions given the premelt distribution and the accumulated melt. This scheme has the advantage of using the observable coefficient of variance (CV) as the only input parameter to determine the shape of the distribution. However, the assumption of uniform melt is not necessarily a good approximation (Pomeroy et al. 2004), and it has been demonstrated that certain numerical criteria are not met for distributions with $\mathrm{CV}$ values larger than about 0.75 (Swenson and Lawrence 2012). Finally, the scheme requires a clear distinction between the accumulation season and the melting season, where snow accumulation during the melting season is accounted for in an ad hoc way.

In this study we introduce and test a tiling approach to simulate subgrid snow variations. This method is similar to the mosaic approach implemented in several LSMs to represent different land surface types on subgrid scales (e.g., Avissar and Pielke 1989; Koster and Suarez 1992), but assumes different snow accumulation in each tile by scaling solid precipitation according to a probability distribution function. This method differs from the probability distribution scheme described above (Liston 2004) in that the distribution is applied continuously to the snow input in the LSM, rather than once to the total accumulated snow. It therefore does not require a distinction between snow accumulation and snowmelt seasons. The use of individual tiles with individual soil columns also means that variations in other variables affected by snow are accounted for. This includes variations in soil moisture and soil temperature that can affect land-atmosphere exchange processes long after the snow has melted.

The method is tested in the Weather Research and Forecasting (WRF) Model with the Noah LSM and is applied to the high-mountain regions of southern Norway at 3-km grid spacing for a full year from September 2011 to September 2012. The scaling of snow accumulation within each grid cell is based on lognormal distributions estimated for this region by Gisnås et al. (2016), based on terrain sheltering indexes (Winstral et al. 2002) calibrated with observed snow distributions at snow maximum. The results are compared to a reference simulation with the standard representation of SCF in WRF-Noah, to observations from a field site, and to a gridded observational dataset.

\section{Models and setup}

The WRF Model (Skamarock and Klemp 2008) is a mesoscale NWP model that is widely used for operational weather forecasting, weather research, and regional climate simulations, with a large number of different physical parameterization options. Here, we apply WRF with two one-way nested domains with 15and 3-km grid spacing, respectively (Fig. 1), and with 60 vertical layers up to a model top of $50 \mathrm{hPa}$. The Noah LSM, used as the lower boundary condition for the atmosphere, simulates four soil layers down to a depth of $2 \mathrm{~m}$ below the surface, with the snowpack treated as a part of the upper soil layer (Ek et al. 2003), and with a single (blended) SEB for snow-covered and snow-free fractions. Since version 3.6, the WRF-Noah modeling system offers the option to include a mosaic approach to represent different land classes within each grid cell (Li et al. 2013), which is here exploited for implementing the subgrid snow tiling.

Other physical parameterizations used in our simulations broadly follow those used by Aas et al. (2015): cloud microphysics is simulated with the two-moment Morrison scheme (Morrison et al. 2005). The short- and longwave radiation are simulated with the Rapid Radiative Transfer Model for GCM applications (RRTMG; Iacono et al. 2008). The Mellor-YamadaJanjić (MYJ) scheme is used to simulate the atmospheric boundary layer, in conjunction with the Eta surface-layer scheme (Janjić 2002). In the coarseresolution domain, cumulus convection is parameterized with the Kain-Fritsch scheme (Kain 2004). Boundary conditions are taken from ERA-Interim 
(a)

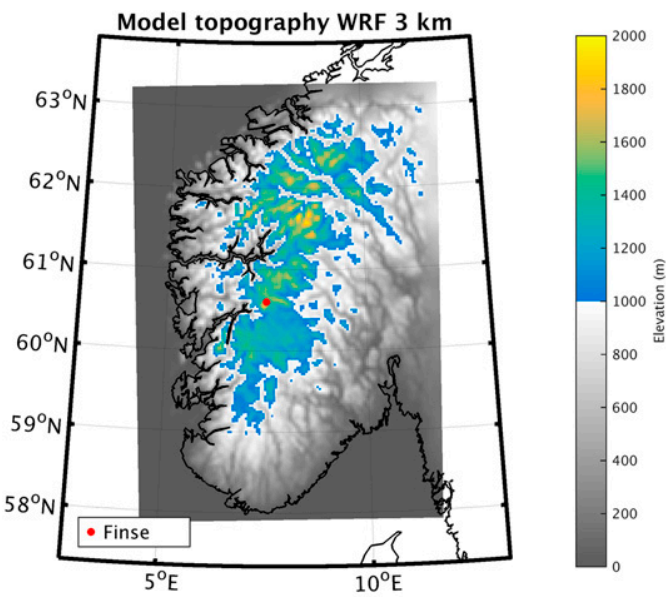

(b)

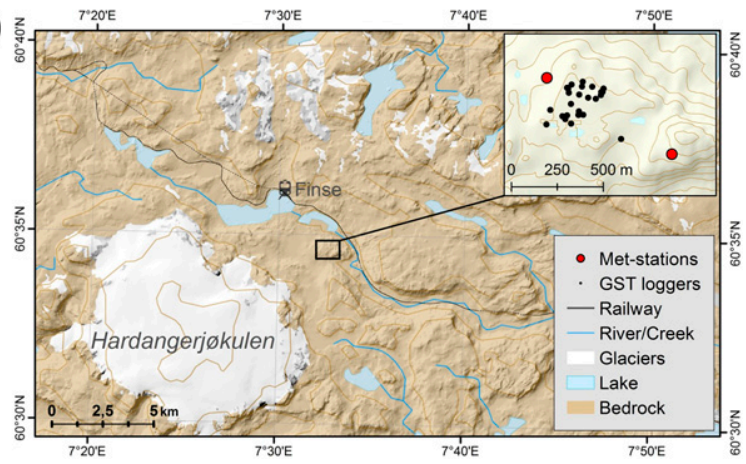

FIG. 1. (a) Innermost WRF Model domain $(3 \mathrm{~km})$ with model topography. Colored area shows elevations $>1000 \mathrm{~m} \mathrm{MSL}$ and the red dot indicates the location of Finse. (b) Finse field site with surroundings. Red and black dots show locations of automatic weather stations (AWSs) and temperature loggers, respectively.

(Dee et al. 2011), updated every 6h. ERA-Interim is also used as the initial condition at the beginning of the simulation, after which the model was run transiently without reinitialization or nudging. Finally, to avoid problems with numerical instabilities due to high vertical velocities along the steep topography at the west coast of Norway, the vertical velocity dampening option (w_damping) in WRF was turned on.

\section{a. Subgrid tiling}

In the original mosaic tiling formulation in WRFNoah (Li et al. 2013), each grid cell is divided into a userspecified number of tiles $N$ with different land types. Each tile receives the same grid-average atmospheric forcing but is simulated individually with its own set of state variables from the surface through the four soil layers. The surface variables needed for the coupling with WRF are derived as averages of all tiles within each grid cell. For most parameters (e.g., sensible and latent heat fluxes, emissivity, and albedo) this is simply computed as the area-weighted average of all of the tiles. For skin temperature and surface roughness length, the following two equations are used, respectively:

$$
\bar{T}=\left(\sum_{i=1}^{N} \varepsilon_{i} T_{i}^{4} A_{i} / \sum_{i=1}^{N} \varepsilon_{i} A_{i}\right)^{1 / 4}
$$

and

$$
\bar{z}_{0}=\exp \left[\sum_{i=1}^{N} \ln \left(z_{0 i}\right) A_{i} / \sum_{i=1}^{N} A_{i}\right],
$$

where $i$ indicates the tile number, $\varepsilon_{i}$ is the emissivity, $T_{i}$ is the surface temperature, $z_{0 i}$ is the roughness length, and $A_{i}$ is the normalized area of the $i$ th tile. It should be noted that the sensible and latent heat fluxes are simulated in WRF-Noah through bulk transfer formula with stabilitydependent exchange coefficients for heat and moisture (Chen et al. 1997). These exchange coefficients are calculated in the surface layer of the WRF Model rather than the LSM and hence use the gridcell-averaged properties from all the tiles. This means that the same stability is assumed for all tiles in a grid cell, although the fluxes are different because of different temperature and moisture gradients between the individual tiles and the first atmospheric layer. When representing snow variations on scales down to a few meters in wind-exposed regions like high-mountain southern Norway, we take this to be an adequate approximation. However, for larger-scale snow variations or calm conditions, it may be better to calculate individual exchange coefficients for each tile. This would likely increase the differences between the tiles, as increased stability would delay the melt of the tiles with the largest snow accumulation.

The mosaic tile architecture is utilized for the subgrid snow tiling in this study, but with some important modifications: we use the same (dominant) land surface type for all tiles within a grid cell, implying that without any snow all of the $N$ tiles in a grid cell would be identical. Furthermore, each tile represents an area of identical size. The nonuniform snow distribution within each grid cell is then accounted for by scaling the amount of solid precipitation received by each tile with a scaling factor $f$. For tile number $i$, the amount of snow received during a snow event, represented with a gridcell-averaged snow accumulation $S$, is then given as $S_{i}=f_{i} S$. We assume that no snow is redistributed between different grid cells, so that the average of these scaling factors in each grid cell is equal to 1 . Liquid precipitation (including the liquid fraction of mixed precipitation) is uniformly distributed within a grid cell, implying that the water and energy input from rain-on-snow events is the same in all $N$ tiles.

The scaling factors $f_{i}$ (Fig. 2, top) are based on lognormal probability distribution functions determined by 

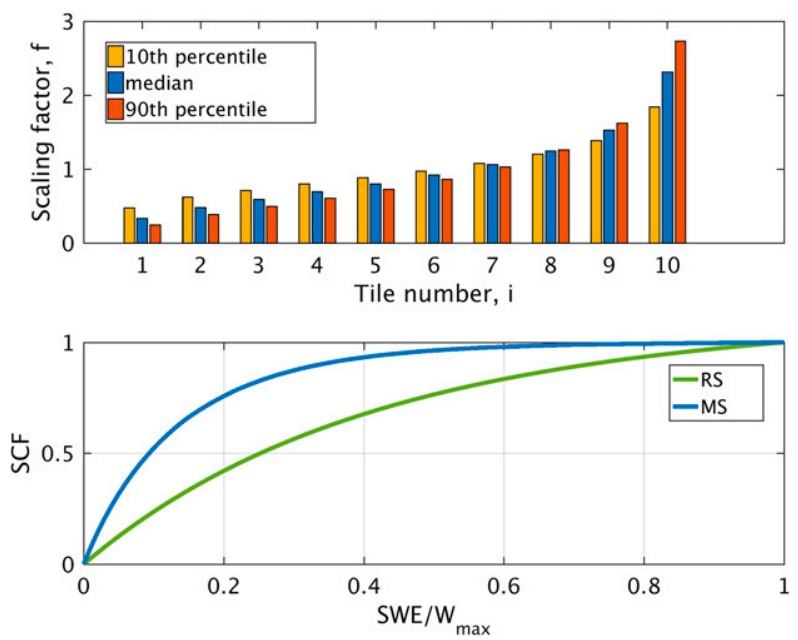

FIG. 2. (top) Scaling factors for the 10th percentile, median, and 90th percentile CV values for all nonvegetated grid cells. (bottom) Gridcell-average SCF in MS and RS as a function of accumulated SWE (before any melt).

$\mathrm{CV}$. These are aggregated into 10 equally sized tiles by calculating mean values for every $10 \%$ of the area from the distribution. Individual CV values were derived for each grid cell from a terrain parameterization (Winstral et al. 2002) over a 10-m-resolution digital terrain model, accounting for wind effects during the accumulation season. The snow distribution scheme, described in detail in Gisnås et al. (2016), is calibrated with snow depth data from a large-scale airborne laser scan (Melvold and Skaugen 2013) conducted over the Hardangervidda mountain plateau in southern Norway. Independent snow distribution observations obtained from groundpenetrating radar surveys were used for validation (Gisnås et al. 2016).

We apply the mosaic snow tiling to nonforested and nonglaciated grid cells only, that is, grassland and tundra. For the analysis we focus on regions above $1000 \mathrm{~m}$ MSL, which are characterized by relatively large snow accumulation and substantial redistribution by wind.

\section{b. Snow cover fraction}

The snow cover fraction in standard Noah is estimated as a function of SWE and a vegetation-dependent reference SWE $W_{\max }$, according to the following equation (Barlage et al. 2010):

$$
\begin{aligned}
\mathrm{SCF}= & 1-\left\{\exp \left(-2.6 \frac{\mathrm{SWE}}{W_{\max }}\right)\right. \\
& \left.-\frac{\mathrm{SWE}}{W_{\max }}[\exp (-2.6)]\right\} .
\end{aligned}
$$

Our subgrid tiling with nonuniform snow distribution makes this SCF parameterization less relevant as the gridcell-average SCF is to a first order determined by the tiles. However, with a limited number of tiles there is still a need for parameterizing SCF within each tile, but in a way that accounts for the fact that this is partially resolved by the tiles. To solve this, we apply the original SCF formulation in Noah within each tile, but with a $W_{\max }$ scaled by the scaling factor for the tile with smallest accumulation $f_{1}$. This gives $W_{\max _{\mathrm{MS}}}=W_{\max _{\mathrm{RS}}}\left(f_{1}\right)$, where MS denotes the mosaic snow simulation and RS denotes the reference simulation. In this way we obtain a gradual transition from fully parameterized SCF (i.e., $N=1$ ) to a more and more resolved SCF, as an increasing number of tiles is associated with a smaller $f_{1}$. In addition, the minimum amount of snow accumulation required to achieve a full snow cover in a grid cell is the same as in the original formulation, although a snow accumulation event smaller than $W_{\max }$ will initially result in a higher SCF (Fig. 2, bottom).

\section{Site description and validation data}

The model is applied to southern Norway, extending from $58^{\circ}$ to $63^{\circ} \mathrm{N}$. Both the topography and climate in Norway are dominated by the Scandinavian mountain range. The landscape in the western parts is dominated by steep mountains and deep fjords, while on the eastern side the mountains are gentler and decrease gradually in height eastward from the ridge. With peaks up to $2469 \mathrm{~m}$ MSL (Galdhøpiggen), the mountain range acts as an effective barrier for the moist air from the Atlantic Ocean. This results in a strong precipitation gradient from the maritime coastal climate, receiving more than $3000 \mathrm{~mm}$ in annual precipitation in some areas, to the more continental and drier climate to the east, where the driest weather stations receive less than $300 \mathrm{~mm}$ of annual precipitation. More than half of the landmass in southern Norway is composed of large plateaus and $\mathrm{u}$-shaped valleys above $600 \mathrm{~m}$ MSL, storing major parts of the precipitation as seasonal snow. As much as $25 \%$ of the area is located above the alpine tree line at elevations higher than $1000 \mathrm{~m}$ MSL. These areas are highly exposed to strong westerly winds from the Atlantic Ocean, resulting in heavy redistribution of the snow cover. Consequently, the mountain catchments feature a long melt season, often lasting longer than 1 month, with related large variations in the timing of runoff (Gisnås et al. 2014).

\section{a. The Finse field site}

Finse (1222 m MSL) is located in the upper part of a valley at the northern margin of Hardangervidda, the largest mountain plateau in northern Europe. Hardangerjøkulen plateau glacier, the sixth-largest 
glacier in mainland Norway, is located a few kilometers south of the field area (Fig. 1b). The area is located within the low alpine zone and is climatically situated in the transition zone between the maritime climate along the west coast and the more continental eastern parts of southern Norway. Maximum summer temperatures normally reach more than $20^{\circ} \mathrm{C}$, while winter temperatures can be lower than $-30^{\circ} \mathrm{C}$. The mean annual air temperature for $1960-90$ was $-2.2^{\circ} \mathrm{C}$, with an average measured annual precipitation of about $1000 \mathrm{~mm}$. However, because of high undercatch at the precipitation gauge, the actual amount of solid precipitation is likely to be between $40 \%$ and $80 \%$ higher (Mohr 2008). More than half of the precipitation falls as snow, normally starting to accumulate in late October, while snowmelt generally lasts until midsummer. The prevailing wind directions are westerly, and the exposed mountain setting in combination with strong winds during winter season results in high spatial variability of snow depths (Gisnås et al. 2014). In 2012, the average snow depth in the field area at snow maximum was around $2 \mathrm{~m}$, with a pronounced spatial variability $(\mathrm{CV}$ close to 1). The bulk snow density, measured in four snow profiles, two at each of the meteorological stations, was relatively high in 2012 (27 February: $400-450 \mathrm{~kg} \mathrm{~m}^{-3}$; 22 March: 472-475 $\mathrm{kg} \mathrm{m}^{-3}$ ).

The modeled SCF was compared to SCF derived from 26 ground surface temperature (GST) loggers distributed over a $500 \mathrm{~m} \times 500 \mathrm{~m}$ area near Finse (Fig. 1; Gisnås et al. 2014). The loggers are installed a few centimeters below the ground surface, logging the temperature with 2-h temporal resolution. The presence of snow at each GST logger was determined from the daily average GST $\left(<0.5^{\circ} \mathrm{C}\right)$ and the diurnal temperature amplitude $\left(<1.0^{\circ} \mathrm{C}\right)$ and variation $\left(<0.4^{\circ} \mathrm{C}\right)$, as described in Lewkowicz (2008). The daily SCF was determined as the fraction of snow-covered GST loggers. The resulting SCFs for the melt season were compared to digital camera images overlooking the area around the Finse research station, located $1.2 \mathrm{~km}$ from the field area (images available online at www.finse.uio.no/news/ webcam/). Furthermore, the images were used to qualitatively evaluate the simulated SCF. Both the temperature loggers and the digital camera images represent areas considerably smaller than the size of a grid cell in our simulation and hence cannot provide the exact SCF for a model grid cell. The length of the melting season in a larger region will, however, not be shorter than what is observed in a smaller area with both of these methods. In situ observations thus provide a minimum time period for the transition from fully snow-covered to snow-free surface conditions. When comparing simulated and observed SCF at Finse, we therefore focus on the length of the period with partial snow cover, rather than the exact values of SCF.

\section{b. SeNorge 2}

The modeled temperature and precipitation fields are evaluated with the seNorge 2 dataset, which is a daily gridded air temperature and precipitation product provided by the Norwegian Meteorological Institute. The dataset is based on in situ observations of air temperature and precipitation from the official climate database, interpolated to $1 \mathrm{~km} \times 1 \mathrm{~km}$ resolution. The interpolation of both variables is performed separately using optimal interpolation (OI). The spatial interpolation relies on the scale-separation concept, where a priori information on the grid is combined with point observations. A priori information is estimated from the observations and serves as a large-scale representation of the data. In the case of temperature, the large-scale field can represent several regional vertical temperature profiles, both allowing for ground-based inversions as well as temporal changes of the vertical profiles at every time step. In a second step, the largescale background field is modified on a local basis by a few neighboring stations, employing an OI as described in Uboldi et al. (2008). A spatial consistency test is included in the spatial interpolation (Lussana et al. 2010).

For precipitation, given the complexity of interaction between scales, a two-step scale-separation scheme has been extended to a multiscale-separation scheme. This is implemented through an iterative OI from the coarser to the local scale, where the parameters of the iterative OI are estimated independently for each precipitation event. For both temperature and precipitation, the actual resolution of the predicted field is specified by the local observation density, which is variable through the spatial domain. For comparison with WRF, we use the average of the nine seNorge2 grid cells within each WRF grid cell.

\section{Results}

To evaluate the effect of the mosaic snow approach, we consider snow (SWE and SCF), 2-m air temperature $T_{2}$, surface energy balance, and precipitation. These variables, both from the mosaic snow (i.e., MS) and the reference (default SCF) simulation (i.e., RS), are compared with observations. We evaluate the results for the Finse field site in detail and for all nonforested, nonglaciated grid cells above $1000 \mathrm{~m}$ MSL in general. Finally, we assess changes in the daily and monthly precipitation on the regional scale, as an indication of the effect of changed snow representation on the coupled land-atmosphere system. 

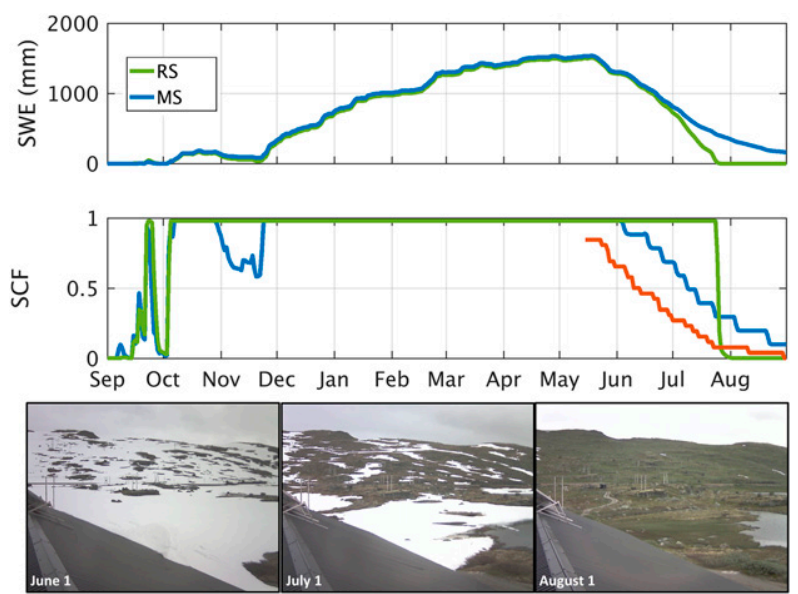

FIG. 3. (top) SWE at Finse from September 2011 to August 2012 simulated with MS and RS. (middle) SCF at Finse from MS (blue), RS (green), and estimated from temperature loggers (red). (bottom) Digital images from Finse field station on $1 \mathrm{Jun}, 1 \mathrm{Jul}$, and 1 Aug 2012.

\section{a. Finse field site}

The difference between MS and RS is most pronounced during snowmelt periods. At Finse, this becomes evident both for a minor melt event in November and the main melt period beginning in mid-May (Fig. 3). In November, both simulations show a period of melt, but only MS shows a reduction in SCF. This drop in snow cover is confirmed by automatic camera images, which show a substantial reduction in SCF in November. Both simulations show about the same maximum SWE, the same onset of snowmelt in mid-May, and a similar melt pattern until early June. After that, the first tiles in MS start to become snow free. From this point on, MS shows a slower melt rate as the snow is confined to a smaller area than in RS, despite the albedo being larger in RS during most of this period (not shown). This results in a significantly longer melt period in MS, with substantial amounts of snow remaining throughout summer and a partial snow cover lasting from early June until the end of summer. Although showing an earlier onset of melt, both the automatic camera images (Fig. 3, bottom) and the temperature loggers (Fig. 3, middle) indicate a period with fractional snow cover similar in length as MS. This is in sharp contrast to RS, which shows a transition time from full snow cover to completely snow-free ground of just a few days.

The late bias in snowmelt seen in both simulations is in agreement with an apparent positive bias in snow accumulation: estimates of SWE from snow pits and ground-penetrating radar at two times late in the accumulation season indicate that the maximum SWE in both simulations could be $400-500 \mathrm{~mm}$ too high. This

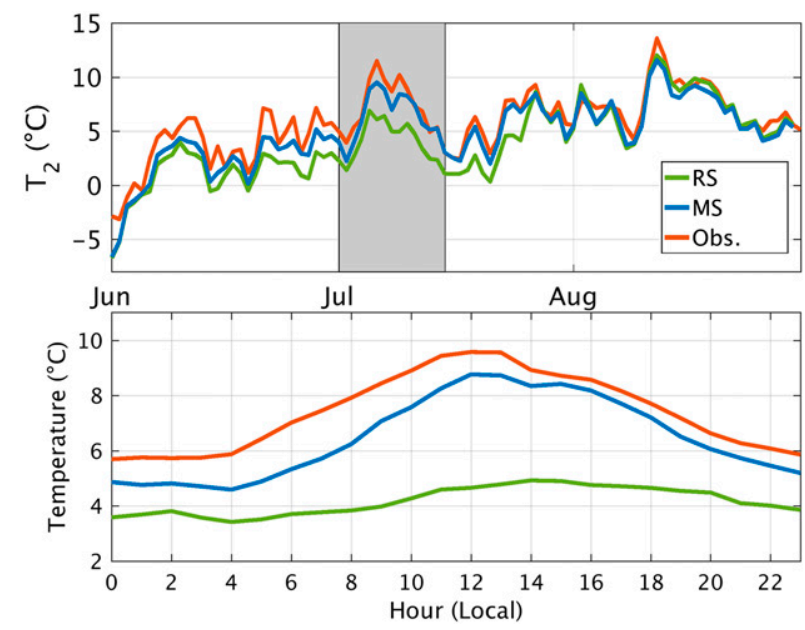

FIG. 4. (top) Daily mean temperature at Finse from RS (green), MS (blue), and observations (red). Observed temperatures are taken as the average of the two automated weather stations at the field site (Fig. 1b). (bottom) Diurnal temperature cycle at Finse during the first 15 days of July (shown as gray area in top).

could be a result of local conditions not captured by the model or a more general overestimation of precipitation in the whole region. On the other hand, it could also be a result of the observations representing only a small (and possibly unrepresentative) part of the model grid cell. In RS, this late bias in snowmelt probably delays the transition from snow-covered to snow-free ground by about two weeks. In MS, it likely shifts the entire melt period, but with a stronger effect in the tiles with larger accumulation. This can therefore explain why snow remains throughout the whole summer in one tile, which is not seen in the automatic camera images and the GST loggers.

The effect of subgrid tiling and partial snow cover is clearly visible in the air temperature in the melting season (Fig. 4). The large negative $T_{2}$ bias seen in the reference simulation is considerably reduced in MS. The mean diurnal $T_{2}$ cycle during the first 15 days of July (Fig. 4, bottom) reveals that this is mainly a result of higher daytime temperatures in the observations and MS. While RS shows only a mean diurnal temperature difference of about $1^{\circ} \mathrm{C}$, the observations and MS yield $4^{\circ} \mathrm{C}$ during this period. In addition, MS shows an earlier peak in daytime temperature than the reference simulation, which is also in better agreement with observations.

The surface energy fluxes differ substantially between the two simulations, as well as between the individual tiles in MS (Fig. 5). The appearance of snow-free tiles from early June results in a higher total sensible heat flux (Fig. 5a) and latent heat flux (Fig. 5b) to the atmosphere in MS. From late July, the ground becomes snow free in 
(a)

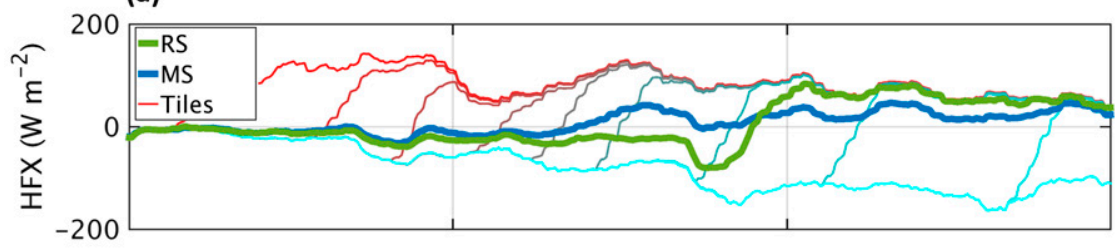

(b)
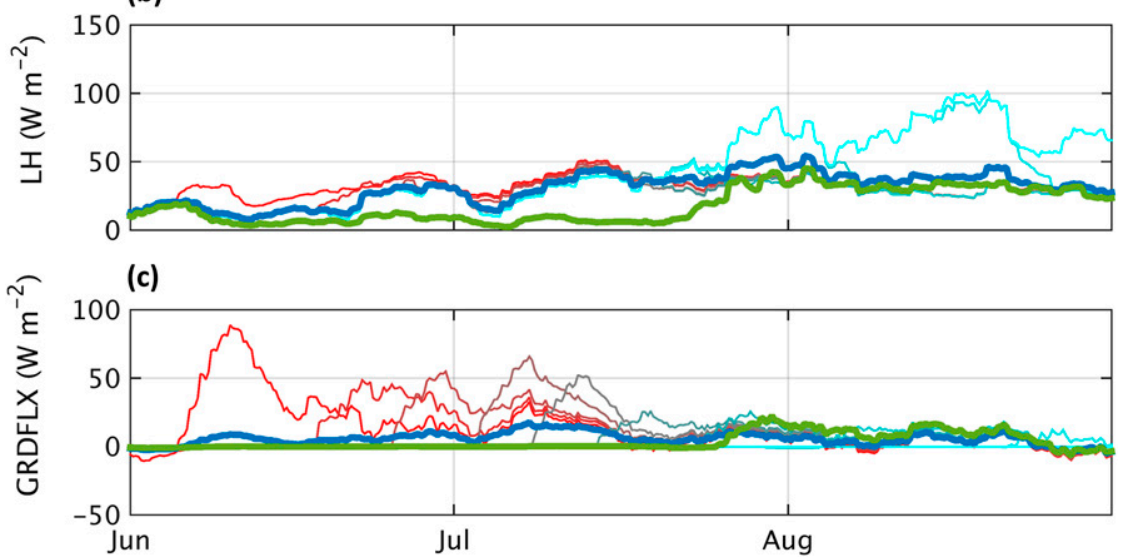

FIG. 5. Simulated sensible heat flux (HFX), latent heat flux (LH), and ground heat flux (GRDFLX) at Finse between 1 Jun and 31 Aug 2012 shown as 5-day running averages. (a) HFX with (blue) and without (green) snow distribution tiles. Each individual tile is shown with thin lines from red (low snow accumulation) to cyan (high snow accumulation). (b) As in (a), but for LH. (c) As in (a), but for GRDFLX.

RS, leading the sensible heat flux to abruptly rise above the level shown by MS, where it remains for the rest of the season. In contrast, the latent heat flux is larger in MS throughout the season, which represents a consistently larger flux of moisture to the atmosphere when subgrid snow tiles are included. Early in the summer season, this increase comes from the snow-free tiles that become warmer and evaporate more water, whereas an increased sublimation from the snow-covered tiles is responsible for the larger moisture flux toward the end of the summer (Fig. 5b). However, it must be noted that Noah has been found to simulate considerably larger snow sublimation than other LSMs in previous studies (Sheffield et al. 2003; Chen et al. 2014). It is therefore possible that the large positive latent heat fluxes from the snow-rich tiles in August are too high, especially considering that the atmosphere is typically relatively warm and moist in this region in late summer.

Another distinct difference between the two simulations is a larger ground heat flux/snow heat flux in MS than in RS (Fig. 5c). In particular, the tile with the smallest snow accumulation (thin red line) absorbs a large amount of energy during the first weeks after it becomes snow free. On the other hand, this tile loses more energy to the atmosphere during the winter season (not shown) as the shallower snowpack provides less insulation from the colder atmosphere. In general, it is clear that accounting for different SEB for snowcovered and snow-free ground has a substantial effect on the energy and moisture fluxes, especially during the transition period from snow-covered to snow-free conditions. However, the ground heat flux is also affected during other times of the year.

\section{b. High-mountain areas of southern Norway}

A more or less binary SCF is found on the regional scale in RS. Figure 6 shows the SCF on 15 June, 15 July, and 15 August in both simulations, displaying very few grid cells with partial snow cover in RS, but large areas with partial snow cover in MS. Comparing the corresponding daily mean temperatures with the gridded observational dataset seNorge2 (Fig. 7) reveals that this binary SCF in RS results in a bimodal temperature pattern in this region. On all three dates RS shows a clear distinction between $T_{2}$ values at snow-covered and snow-free grid cells, with a very small overlap and a considerable negative bias for snow-covered grid cells compared to seNorge2 temperature data. With the subgrid snow tiling (for which a large number of grid cells feature partial snow cover), this bimodal pattern is removed and a more continuous range of temperatures is simulated. In June and July the cold bias is reduced by 

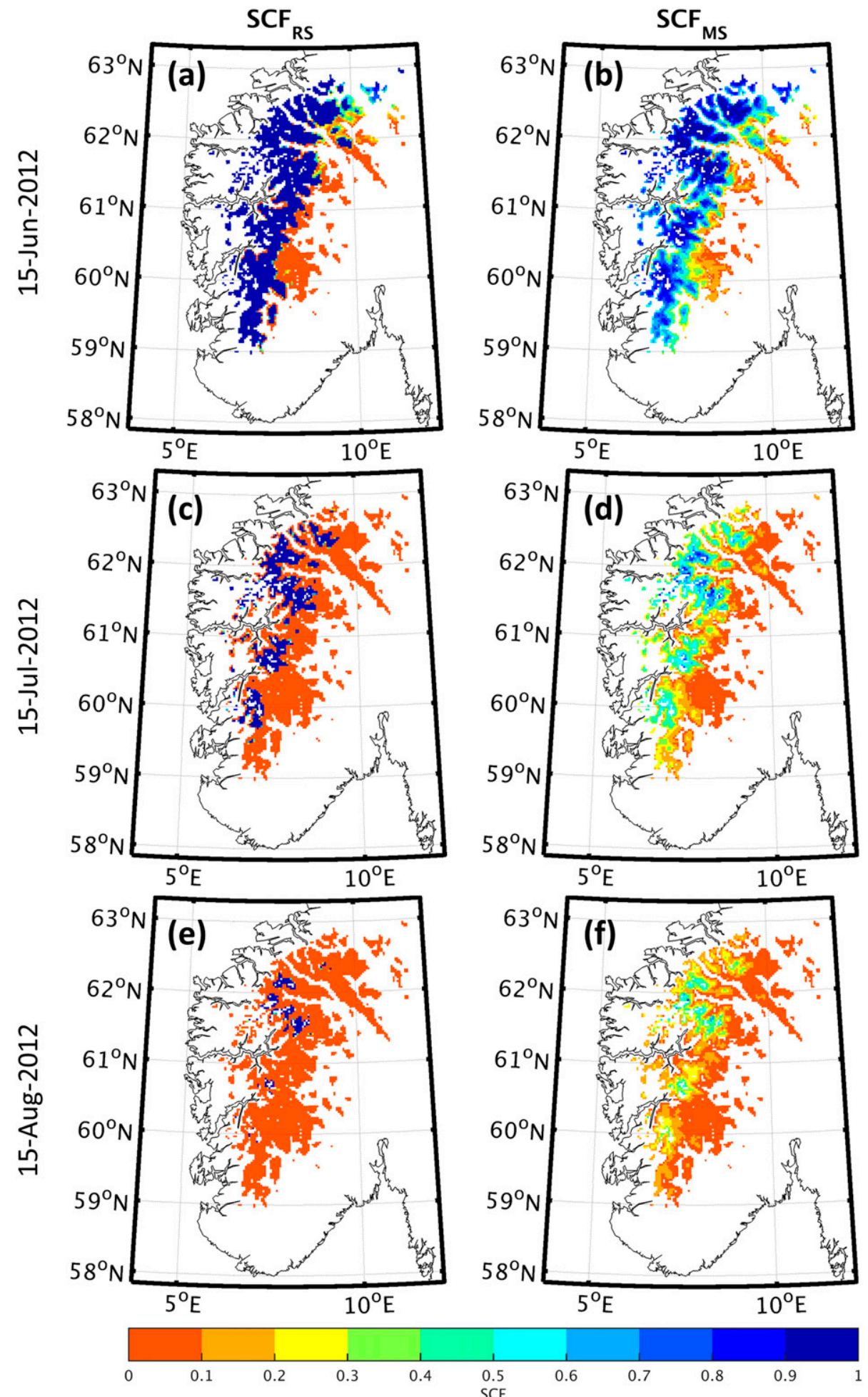

FIG. 6. SCF on (a),(b) 15 Jun; (c),(d) 15 Jul; and (e),(f) 15 Aug for (left) RS and (right) MS. 

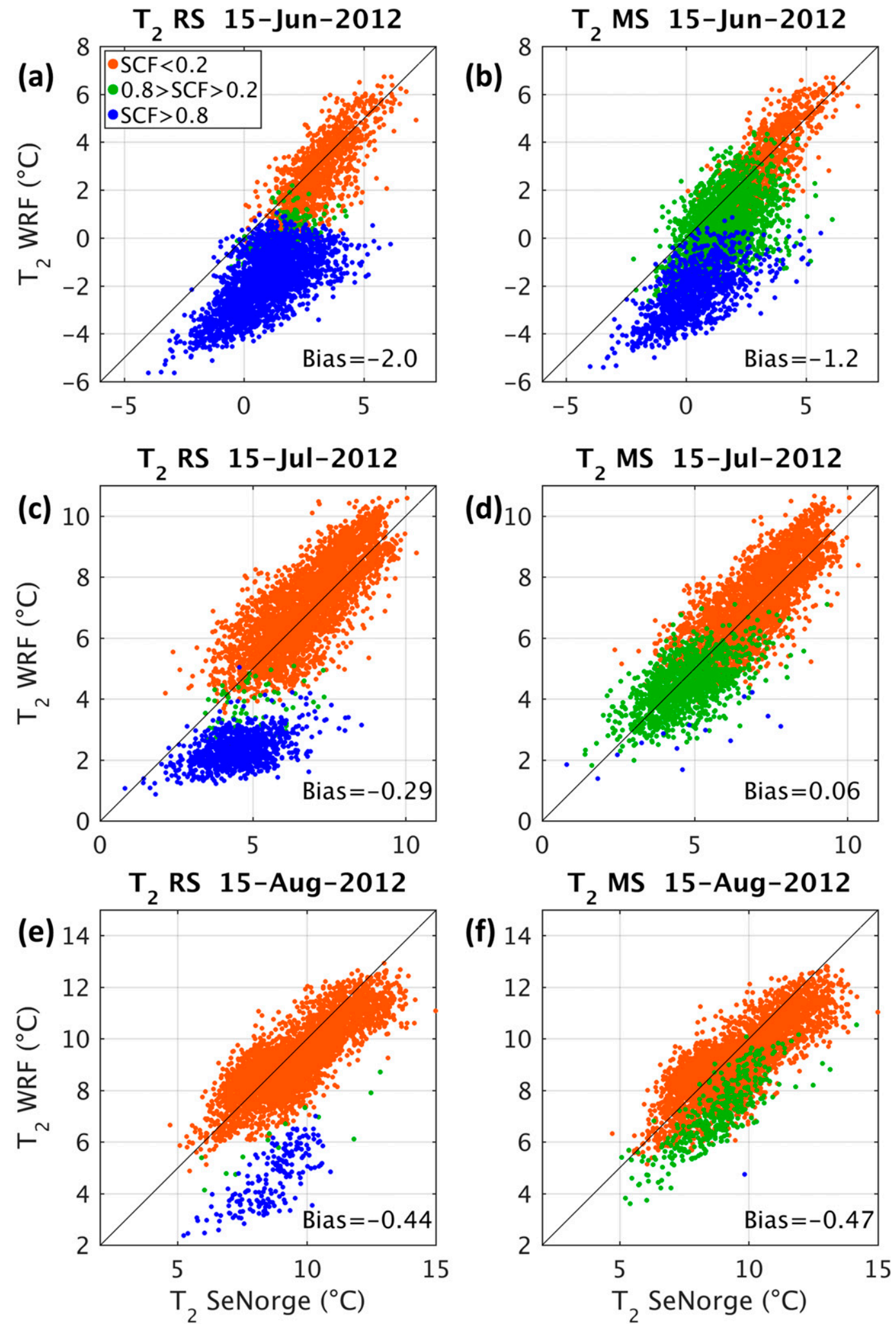

FIG. 7. Daily mean temperatures at each nonvegetated and nonglaciated grid cell above $1000 \mathrm{~m}$ on (a),(b) 15 Jun; (c),(d) $15 \mathrm{Jul}$; and (e),(f) 15 Aug for (left) RS and (right) MS. Color of dots indicates amount of snow cover in the respective grid cell: red, SFC $>0.8$; green, SCF 0.2-0.8; and blue, SCF $<0.2$. 

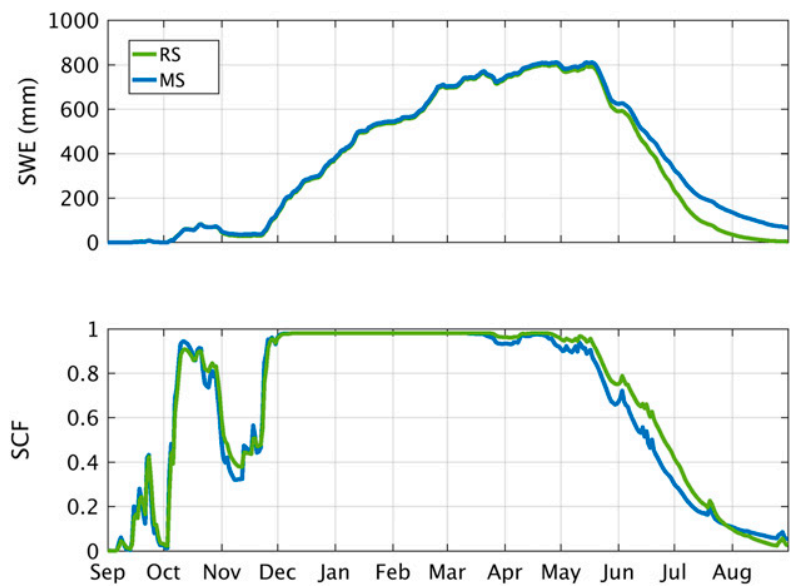

FIG. 8. (top) SWE averaged over nonvegetated, nonglaciated grid cells above $1000 \mathrm{~m}$ simulated with MS and RS. (bottom) As in (top), but for SCF.

$0.8^{\circ}$ and $0.2^{\circ} \mathrm{C}$ in MS, respectively, while the difference in average bias is small in August.

Figure 8 displays the mean SWE and SCF in the region shown in Fig. 6. The regional averages roughly follow the pattern of the Finse field site (Fig. 3), with some differences between the two simulations during the small melt period in November, but otherwise very similar results up until the main melt season. From the start of the main melting season about mid-May, both average SCF and melt rate are higher in RS. This continues until late July, when the average SCF becomes larger in MS: in RS almost all grid cells have become snow free by this time, while snow is still present in MS (but confined to a few tiles in each grid cell). Although the differences between RS and MS are smaller for the averages over a larger region (including different elevations and snow amounts) compared to an individual grid cell, the slower melt and larger amount of snow remaining late in the summer are characteristic features of MS compared to RS. In addition, the SCF and albedo are higher in MS during most of the melt season.

The average SEB over the region and the difference in albedo between the two simulations are shown in Fig. 9. With the exception of energy consumed by snowmelt, all energy fluxes have larger magnitudes in MS during most of the melt period (May-July), with the largest increases found for sensible ( $43 \%)$ and latent $(45 \%)$ heat fluxes in June. This is a combined effect of lower albedo in MS during most of the melting season (Fig. 9, bottom), resulting in more absorbed solar radiation, and the snowfree areas, allowing for larger average skin temperatures with corresponding higher longwave outgoing radiation and turbulent fluxes to the atmosphere. From early August, the albedo in MS becomes larger than in RS

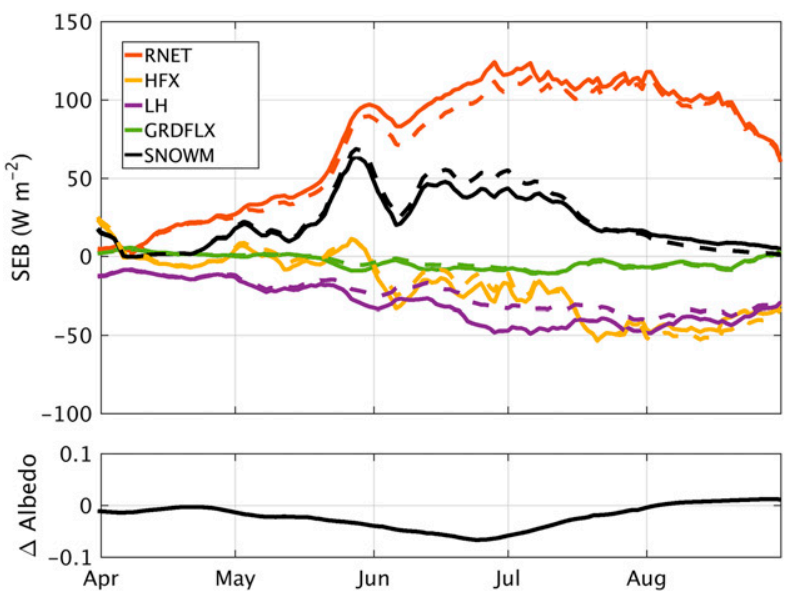

FIG. 9. (top) SEB fluxes averaged over all nonvegetated and nonglaciated grid cells above $1000 \mathrm{~m}$ shown as 10-day running averages. Solid and stippled lines represent MS and RS, respectively. Positive values represent fluxes to the surface. In the legend, RNET represents net radiation and SNOWM represents snowmelt. (bottom) Albedo difference (MS - RS) in the same region as in top.

because of the larger amount of snow remaining in the domain (Fig. 8), which also leads to smaller sensible heat flux. However, similar to the findings for Finse, the latent heat flux is consistently larger in this mountain region throughout the summer, probably because of sublimation from the remaining snowpack and higher soil moisture content leading to increased evaporation.

\section{c. Regional precipitation}

We evaluate the effect of enhanced energy and moisture fluxes on the coupled land-atmosphere system by comparing the precipitation fields of the two simulations to each other and to observations. Although the relationship between surface energy and moisture fluxes and precipitation is highly nonlinear, this gives an indication of the impact of introducing snow tiles on the mesoscale weather. To quantify this effect, we compare the accumulated monthly precipitation during June (Fig. 10), which is the month with the largest difference in surface fluxes between the two simulations (Fig. 9). In most of the domain, the changes in precipitation are not statistically significant when comparing daily precipitation changes over a month. However, in the region where the difference in SCF is most pronounced (see Fig. 6), a considerable area with increased precipitation is found, which is statistically significant within a $95 \%$ confidence interval (CI) generated via bootstrapping (Fig. 10b). To compare these changes to the gridded observational dataset (seNorge2), we average over a larger region surrounding this area (see Fig. 10). Within this region, an increase in mean daily precipitation from 
(a)
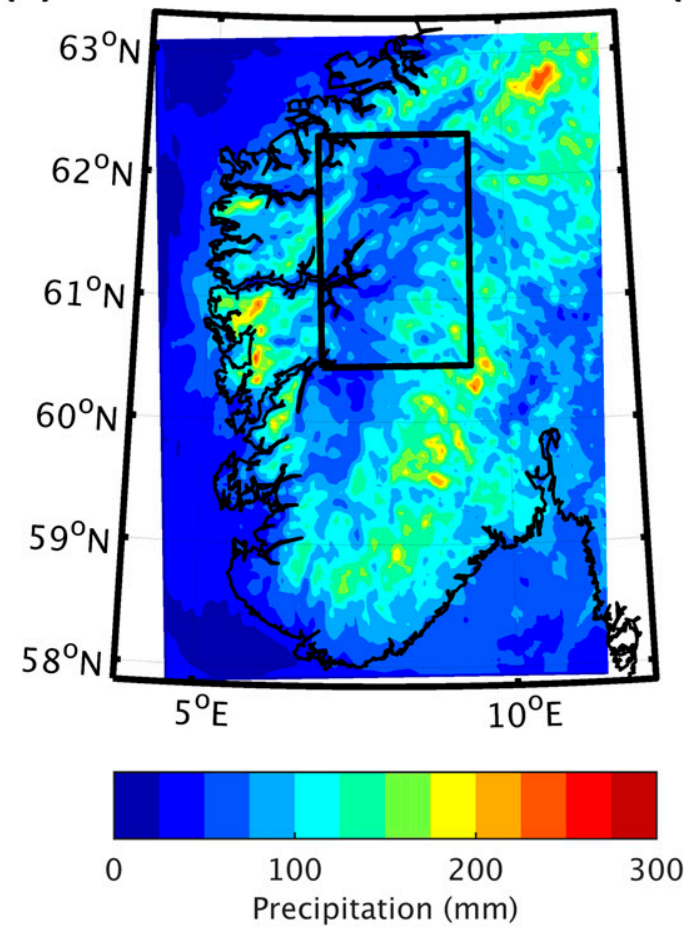

(b)

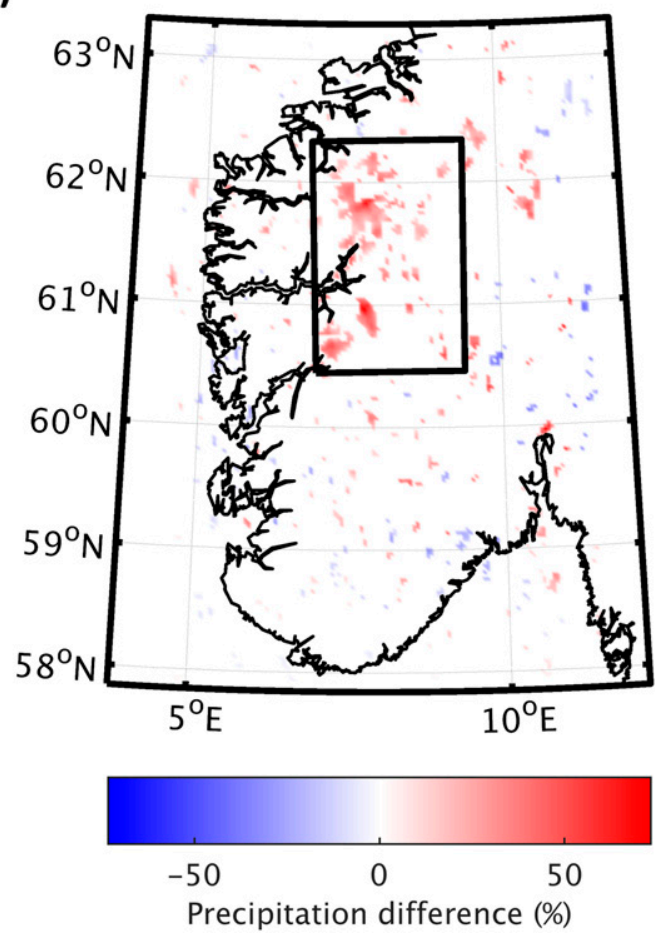

FIG. 10. (a) Simulated precipitation in 3-km domain during June 2012 in the MS. (b) Difference in precipitation between MS and RS during June 2012 in the 3-km domain, significant to the $95 \%$ confidence level using a paired Student's $t$ test.

2.4 (with a range of 1.8-3.2) $\mathrm{mm}$ to 2.7 (with a range of 2.0-3.2) $\mathrm{mm}$ is found (intervals showing $95 \%$ CI from bootstrapping), which is accompanied by an increased correlation with daily precipitation from seNorge 2 from 0.83 (with a range of $0.74-0.91$ ) to 0.89 (with a range of 0.82-0.95). Although not statistically significant, this suggests that the enhanced precipitation observed in Fig. 10b is in better agreement with precipitation estimated from observations.

\section{Discussion}

The standard SCF formulation in Noah is not capable of simulating the extended snowmelt season in the southern Norwegian mountain areas properly. While both automatic camera images and temperature loggers indicate partially snow-covered ground for more than 2 months at Finse, the model simulates this transition within a few days in RS, both at Finse and in the studied mountain region in general. With the introduced method of subgrid tiles, this transition time is substantially increased, resulting in a much larger number of partially snow-covered grid cells in the whole region. This results in higher mean temperatures with larger amplitude of the diurnal cycle, increased SEB fluxes with up to $45 \%$ increase in latent heat flux, more snow remaining in late summer, and more than $50 \%$ increase in monthly precipitation in the most affected areas. Compared to observations, the temperature changes and the increased duration of fractional snow cover are substantial improvements, while the changes in energy and moisture fluxes remain to be validated. The latter represent important changes in the coupled landatmosphere system and the surface and subsurface hydrology, but fewer observations exist for validation. Similarly, the changes in precipitation were found to be statistically significant only in localized regions, and comparison with observations can only give a weak indication that this represents an improvement of model performance. However, the mean precipitation increase in the subregion shown in Fig. 10 (about $7.5 \mathrm{~mm}$ ) corresponds quite well with the mean increase in evaporation/ sublimation in the region with snow tiles (about $10 \mathrm{~mm}$ ) in June, suggesting a strong link between these changes.

Altogether, the results suggest that the subgrid tiling approach offers a significant improvement over the standard Noah SCF scheme, both on local and regional scales. The question then arises if similar model improvements could be achieved by tuning the current SCF parameterization or by replacing it with a more 
advanced parameterization, avoiding the computational cost of simulating a number of tiles in each grid cell.

\section{a. Comparing the tiling approach to other SCF schemes}

The SCF algorithm in Noah is relatively simple, requiring only SWE and $W_{\max }$. Based on Fig. 3, $W_{\max }$ must be increased to about $1300 \mathrm{~mm}$ (50 times its current value!) in order to attain a partial snow cover at Finse in early June, as obtained in MS. Such an increase is clearly not applicable for other tundra regions where the snow accumulation is smaller. This is a general problem with formulations that relate snow cover to a fixed reference SWE or snow depth. These schemes cannot reproduce the observed hysteresis effect between accumulation and melt and will generally yield a too low SCF in the accumulation season or a too high SCF in the melting season in regions with high snow accumulation.

To account for a hysteresis effect, several schemes use a functional dependency of SCF on the snow density, for example, Noah-MP (Niu et al. 2011) and HTESSEL (Dutra et al. 2010). Snow density is used as a proxy for snow age, so that denser snow (typical for the melting season) results in a lower SCF than for the same snow depth with lower density. As pointed out by Swenson and Lawrence (2012), the relation between SCF and snow density is not clear from a physical point of view, as the fractional snow cover observed during snowmelt is a result of horizontal inhomogeneity rather than vertical compaction of the snow. Furthermore, Wrzesien et al. (2015) found that the SCF scheme in Noah-MP also resulted in a binary SCF in the mountain region of the Sierra Nevada with the default parameters in WRF-Noah-MP, although Noah-MP has a more sophisticated SCF scheme than Noah. They found that extensive tuning of the scheme was required to match the observed spread in SCF values during early winter, which in turn resulted in too early snowmelt. It therefore seems that this SCF scheme is not able to capture the observed SCF in regions with large snow accumulation and a long transition period from snow-covered to snow-free ground.

Another way of accounting for the hysteresis effect is to relate SCF to the ratio of SWE to the maximum SWE during the melt season, as in the newer versions of CLM (Swenson and Lawrence 2012) and RCA (Samuelsson et al. 2015). This allows for fractional snow cover quickly after the onset of snowmelt, even when the SWE is large, in agreement with observations for Finse (Fig. 3). In Noah this could be achieved by setting $W_{\max }$ to the maximum value of SWE. However, a problem with this approach arises when periods of melting and accumulation interrupt each other as observed at Finse (Fig. 3). This issue also arises with SCF schemes that assume a probability function for snow distribution that is combined with the average snowmelt to find the SCF at any given time, as done by Liston (2004).

With the tiling approach, the hysteresis effect is well represented without additional assumptions when accumulation and melt are alternating. This also allows for independent development of the snowpack in each tile. For instance, the snow that remained during the melting episode at Finse in November 2011 (Fig. 3) will have different properties than the fresh snow arriving later in the accumulation season. Even with the relatively simple snow physics in Noah, this results in varying snow density between the individual tiles. With more advanced snow schemes the effect of using tiles could become even more important, as individual snow temperature and moisture conditions would be resolved for each tile. By capturing this, as well as variations in subgrid soil temperatures and moisture, the mosaic approach has the potential to even simulate varying melt rates on subgrid scales, to the extent that this is related to the history and properties of the snowpack itself. This is therefore an improvement over the assumption of uniform melt (e.g., Liston 2004), although the main processes leading to nonuniform melt rates are usually related to variations in energy input from the atmosphere, which is not accounted for here.

Another improvement is the representation of individual SEB in the individual tiles. While some LSMs simulate individual SEBs for a snow-covered and snowfree fraction, Fig. 6 shows that the individual tiles behave differently also after the snow has melted. The importance of these differences will vary from region to region and on the overall objective of the simulation. For NWP applications, in general only the average fluxes of energy and moisture are of interest. These fluxes were substantially different in our mosaic simulation, but it is possible that a similar performance could be achieved with an improved SCF scheme introducing separate snow-covered and snow-free SEB simulations. For other applications, like climate simulations where thawing of permafrost and related release of carbon from the soil is important (Schuur et al. 2008; McGuire et al. 2009), the subgrid variations in soil properties would be important to capture. In summary, a number of physical processes related to variations of snow depths in subgrid scales are explicitly accounted for with the mosaic snow approach. It therefore provides a more physical representation of subgrid variations related to snow than standard SCF formulations.

\section{b. Guidance for future applications}

The mosaic snow approach offers the possibility to use any observed, modeled, or in other ways assumed snow 
distribution, without any constraint to its shape. The limitation is the number of tiles, which must be selected to balance the added computational cost against the added value of resolving a larger number of snow depths.

With the 10 tiles used in this study, we found an increase in wall clock computation time of $2 \%-3 \%$. This is substantially less than the $15 \%$ increase found by $\mathrm{Li}$ et al. (2013) for eight tiles using the same tiling method. The relative increase in computational time depends on the number of grid cells that the tiling is applied to and the overall computational cost of the other components of the model. As we simulated more than twice as many vertical layers in the atmosphere as $\mathrm{Li}$ et al. (2013) (60 compared to 28), and only applied the tiling to about $42 \%$ of the finest (and not the parent) domain, a smaller relative increase was expected. The amount of added computational cost that can be afforded will depend on the purpose of the simulation. However, compared to increasing the horizontal resolution, the tiling approach represents a very modest increase in computational cost even if applied to all grid cells. If computational resources are limited, this method could be applied only for parts of the year (in particular the melting season), but the effects of spatially variable snow and soil properties for the other time periods could then not be simulated.

The number of tiles used is in principle unlimited. Figure 3 (bottom) indicates that the SCF curve is highly dependent on this number in our simulation, but a considerable improvement over the default formulation should be possible even with just a few tiles. This has been confirmed with simulations of SCF using a simplified model with idealized accumulation and melt. This method should therefore be explored further, although a larger number of tiles are probably needed to simulate the average albedo and energy fluxes more accurately. Furthermore, if the aim is to simulate the exact amount of SWE at any given point in time, or the exact timing of the complete melt-out of snow in a region, the number of tiles would have to be increased even further. It would then be relevant to use tiles with different areal fractions to better represent the tails of the distribution. However, the inaccuracies introduced with a limited number of tiles is likely to quickly become small compared to the uncertainty in winter accumulation or input distribution used to define the scaling factors, even for a low number of tiles.

In our simulations we use the lognormal distribution with the single shape parameter as basis for the scaling factors. The lognormal distribution is commonly used to describe subgrid snow variations, and the shape parameter, $\mathrm{CV}$, is reported in a large number of observational studies (Liston 2004; Clark et al. 2011; Winstral and Marks 2014). Based on the work of Gisnås et al. (2016), we have here used spatially variable distributions, applied only to nonforested, nonglaciated grid cells. However, we note that the input distributions are relatively similar (Fig. 2, top), and using a single CV value based on observations would probably be a satisfactory option in most cases. Typical CV values for different land categories are provided by Liston (2004) and Clark et al. (2011), offering a good starting point to define snow distributions in areas where direct observations are not available. Both of these studies also include CV values for forested regions. Although the current study applies the tiling only to nonforested grid cells (i.e., the environment for which the distributions were compiled from field observations), the method introduced here should be applicable to regions with more pronounced vegetation as well. Similarly, we have here applied the method only to the fine $(3 \mathrm{~km})$-resolution domain. Basing the input distributions on terrain sheltering indexes would be less relevant in the coarse $(15 \mathrm{~km})$-resolution domain, as the snow distribution is dominated by other factors on this scale. Nevertheless, the concept should again be applicable on this and even larger scales, given that appropriate input distributions are available. In general, larger or more topographically rugged regions might be better represented by a combination of several lognormal distributions (Kerr et al. 2013) or broader distributions (Swenson and Lawrence 2012). Development of scale and topographically dependent distributions would therefore be desirable in order to generalize the current method. Compared to the reference simulation with the default Noah SCF scheme, the snow tiling approach appears to offer an improvement for even a small number of tiles and with a quite uncertain input distribution.

\section{c. Extension to multivariate mosaic approaches}

The study region is characterized by little or no vegetation and high wind speeds, resulting in relatively broad snow distributions. Snow is therefore a dominant factor for subgrid variations in SEB, especially during the snowmelt period (Gisnås et al. 2014). However, in many regions, subgrid variations on the surface are dominated by other factors, such as variations in vegetation type and cover, as well as elevation. Several studies have therefore explored the possibilities for multivariate mosaic schemes (Fiddes and Gruber 2012; Newman et al. 2014). Such approaches have the potential to capture subgrid variations of several parameters with a relatively small increase in computational time. However, such schemes might underrepresent the variation of snow depths within a grid cell unless the 
processes involved in the redistribution of snow are adequately accounted for. In some cases it may therefore be better to directly input the assumed distribution similarly to what is shown here.

\section{Conclusions}

In this study, we have tested a mosaic approach to represent subgrid snow variations by distributing solid precipitation in subgrid tiles based on predefined snow distributions. The results were evaluated with a reference WRF-Noah simulation as well as point and gridded observations in the high-mountain region of southern Norway. These comparisons revealed a number of improvements with the mosaic snow approach.

The transition time from fully snow-covered to snowfree ground is increased from a few days to several months, in agreement with in situ observations. This improved representation of the fractional snow cover reduces a cold temperature bias found in the reference simulation during the melting season both at point and regional scales. At the Finse field station the temperature bias at local noon was reduced by $4^{\circ} \mathrm{C}$ during the first half of July, accompanied by an improved representation of the phase of the diurnal temperature cycle. On a regional scale, the mosaic snow approach removed the bimodal temperature pattern observed in June, July, and August, related to the almost binary SCF in the reference simulation. Furthermore, average biases were reduced by $0.8^{\circ}$ and $0.2^{\circ} \mathrm{C}$ on 15 June and $15 \mathrm{July}$, respectively.

Heat and moisture fluxes from the surface were also considerably altered, with larger energy fluxes as a result of decreased albedo and increased skin temperatures during the melting season. However, the moisture flux in the mosaic approach exceeded the reference simulation even after the albedo and temperature became lower in late summer, as a result of more snow remaining throughout summer. The effect of these changes also revealed itself through precipitation increases of up to about $50 \%$ in certain regions.

Some of these improvements could have been achieved by implementation of an improved SCF parameterization, combined with separate calculations of the surface energy balance for snow-covered and snowfree ground. There are, however, additional physical processes related to subgrid snow variations that are accounted for with subgrid tiling. In addition, the presented approach can account for the hysteresis effect while treating the accumulation season and melting season in a consistent way. Hence, it must be regarded as one of the most physically consistent approaches to account for subgrid variations of snow depths in coupled land surface-atmosphere models.
Acknowledgments. This study is part of the CryoMet project funded by the Norwegian Research Council (NFR; project 214465). Preparation of this paper was further supported by the NFR-funded projects ESCYMO (project 244024) and PERMANOR (project 255331), as well as the Nordic Centre of Excellence eScience Tools for Investigating Climate Change at High Northern Latitudes (eSTICC; Nordforsk Grant 57001). Simulations were performed on the Abel Cluster owned by the University of Oslo and NOTUR. The authors are grateful to Cristian Lussana (Norwegian Meteorological Institute) for making the seNorge2 dataset available for this study, to Erika Anita Leslie for the digital images from Finse field station, and to three anonymous reviewers for their valuable comments and suggestions.

\section{REFERENCES}

Aas, K. S., and Coauthors, 2015: A comparison between simulated and observed surface energy balance at the Svalbard Archipelago. J. Appl. Meteor. Climatol., 54, 1102-1119, doi:10.1175/JAMC-D-14-0080.1.

Avissar, R., and R. A. Pielke, 1989: A parameterization of heterogeneous land surfaces for atmospheric numerical models and its impact on regional meteorology. Mon. Wea. Rev., 117, 2113-2136, doi:10.1175/1520-0493(1989)117<2113: APOHLS $>2.0 . \mathrm{CO} ; 2$.

Barlage, M., and Coauthors, 2010: Noah land surface model modifications to improve snowpack prediction in the Colorado Rocky Mountains. J. Geophys. Res., 115, D22101, doi:10.1029/2009JD013470.

Chen, F., Z. Janjić, and K. Mitchell, 1997: Impact of atmospheric surface-layer parameterizations in the new land-surface scheme of the NCEP mesoscale Eta model. Bound.-Layer Meteor., 85, 391-421, doi:10.1023/A:1000531001463.

__ and Coauthors, 2014: Modeling seasonal snowpack evolution in the complex terrain and forested Colorado Headwaters region: A model intercomparison study. J. Geophys. Res. Atmos., 119, 13 795-13 819, doi:10.1002/2014JD022167.

Clark, M. P., and Coauthors, 2011: Representing spatial variability of snow water equivalent in hydrologic and land-surface models: A review. Water Resour. Res., 47, W07539, doi:10.1029/2011WR010745.

Dee, D. P., and Coauthors, 2011: The ERA-Interim reanalysis: Configuration and performance of the data assimilation system. Quart. J. Roy. Meteor. Soc., 137, 553-597, doi:10.1002/qj.828.

Dutra, E., G. Balsamo, P. Viterbo, P. M. A. Miranda, A. Beljaars, C. Schar, and K. Elder, 2010: An improved snow scheme for the ECMWF land surface model: Description and offline validation. J. Hydrometeor., 11, 899-916, doi:10.1175/2010JHM1249.1.

Ek, M. B., K. E. Mitchell, Y. Lin, E. Rogers, P. Grunmann, V. Koren, G. Gayno, and J. D. Tarpley, 2003: Implementation of Noah land surface model advances in the National Centers for Environmental Prediction operational mesoscale Eta model. J. Geophys. Res., 108, 8851, doi:10.1029/2002JD003296.

Fiddes, J., and S. Gruber, 2012: TopoSUB: A tool for efficient large area numerical modelling in complex topography at sub-grid scales. Geosci. Model Dev., 5, 1245-1257, doi:10.5194/ gmd-5-1245-2012. 
Gisnås, K., S. Westermann, T. V. Schuler, T. Litherland, K. Isaksen, J. Boike, and B. Etzelmüller, 2014: A statistical approach to represent small-scale variability of permafrost temperatures due to snow cover. Cryosphere, 8, 2063-2074, doi:10.5194/tc-8-2063-2014.

,,,--- K. Melvold, and B. Etzelmüller, 2016: Small-scale variation of snow in a regional permafrost model. Cryosphere, 10, 1201-1215, doi:10.5194/tc-10-1201-2016.

Iacono, M. J., J. S. Delamere, E. J. Mlawer, M. W. Shephard, S. A. Clough, and W. D. Collins, 2008: Radiative forcing by longlived greenhouse gases: Calculations with the AER radiative transfer models. J. Geophys. Res., 113, D13103, doi:10.1029/ 2008JD009944.

Janjić, Z. I., 2002: Nonsingular implementation of the MellorYamada level 2.5 scheme in the NCEP Meso model. NCEP Office Note 437, 61 pp. [Available online at http://www.emc. ncep.noaa.gov/officenotes/newernotes/on437.pdf.]

Kain, J. S., 2004: The Kain-Fritsch convective parameterization: An update. J. Appl. Meteor., 43, 170-181, doi:10.1175/ 1520-0450(2004)043<0170:TKCPAU > 2.0.CO;2.

Kerr, T., M. Clark, J. Hendrikx, and B. Anderson, 2013: Snow distribution in a steep mid-latitude alpine catchment. $A d v$. Water Resour., 55, 17-24, doi:10.1016/j.advwatres.2012.12.010.

Koster, R. D., and M. J. Suarez, 1992: Modeling the land surface boundary in climate models as a composite of independent vegetation stands. J. Geophys. Res., 97, 2697-2715, doi:10.1029/91JD01696.

Lewkowicz, A. G., 2008: Evaluation of miniature temperatureloggers to monitor snowpack evolution at mountain permafrost sites, northwestern Canada. Permafrost Periglacial Processes, 19, 323-331, doi:10.1002/ppp.625.

Li, D., E. Bou-Zeid, M. Barlage, F. Chen, and J. A. Smith, 2013: Development and evaluation of a mosaic approach in the WRF-Noah framework. J. Geophys. Res. Atmos., 118, 1191811935, doi:10.1002/2013JD020657.

Liston, G. E., 2004: Representing subgrid snow cover heterogeneities in regional and global models. J. Climate, 17, 1381-1397, doi:10.1175/1520-0442(2004)017<1381: $\mathrm{RSSCHI}>2.0 . \mathrm{CO} ; 2$.

Lussana, C., F. Uboldi, and M. R. Salvati, 2010: A spatial consistency test for surface observations from mesoscale meteorological networks. Quart. J. Roy. Meteor. Soc., 136, 1075-1088, doi:10.1002/qj.622.

McGuire, A. D., and Coauthors, 2009: Sensitivity of the carbon cycle in the Arctic to climate change. Ecol. Monogr., 79, 523555, doi:10.1890/08-2025.1.

Melvold, K., and T. Skaugen, 2013: Multiscale spatial variability of lidar-derived and modeled snow depth on Hardangervidda, Norway. Ann. Glaciol., 54, 273-281, doi:10.3189/ 2013AoG62A161.

Mohr, M., 2008: New routines for gridding of temperature and precipitation observations for "seNorge.no." Met.No Note 08/2008, Norwegian Meteorological Institute, 40 pp. [Available online at http://met.no/filestore/NewRoutinesforGriddingofTemperature. pdf.]

Morrison, H., J. A. Curry, and V. I. Khvorostyanov, 2005: A new double-moment microphysics parameterization for application in cloud and climate models. Part I: Description. J. Atmos. Sci., 62, 1665-1677, doi:10.1175/JAS3446.1.

Newman, A. J., M. P. Clark, A. Winstral, D. Marks, and M. Seyfried, 2014: The use of similarity concepts to represent subgrid variability in land surface models: Case study in a snowmelt-dominated watershed. J. Hydrometeor., 15, 17171738, doi:10.1175/JHM-D-13-038.1.

Niu, G. Y., and Z. L. Yang, 2007: An observation-based formulation of snow cover fraction and its evaluation over large North American river basins. J. Geophys. Res., 112, D21101, doi:10.1029/2007JD008674.

, and Coauthors, 2011: The community Noah land surface model with multiparameterization options (Noah-MP): 1. Model description and evaluation with local-scale measurements. J. Geophys. Res., 116, D12109, doi:10.1029/ 2010JD015139.

Pomeroy, J., R. Essery, and B. Toth, 2004: Implications of spatial distributions of snow mass and melt rate for snowcover depletion: Observations in a subarctic mountain catchment. Ann. Glaciol., 38, 195-201, doi:10.3189/ 172756404781814744.

Samuelsson, P., S. Gollvik, C. Jansson, M. Kupiainen, E. Kourzeneva, and W. J. van de Berg, 2015: The surface processes of the Rossby Centre regional atmospheric climate model (RCA4). SMHI Rep. 157, 58 pp. [Available online at http:// www.smhi.se/polopoly_fs/1.89799!/Menu/general/extGroup/ attachmentColHold/mainCol1/file/meteorologi_157.pdf.]

Schuur, E. A. G., and Coauthors, 2008: Vulnerability of permafrost carbon to climate change: Implications for the global carbon cycle. BioScience, 58, 701-714, doi:10.1641/B580807.

Sellers, P. J., and Coauthors, 1996: A revised land surface parameterization ( $\mathrm{SiB} 2)$ for atmospheric GCMs. 1. Model formulation. J. Climate, 9, 676-705, doi:10.1175/1520-0442(1996)009<0676: ARLSPF $>2.0 . \mathrm{CO} ; 2$.

Sheffield, J., and Coauthors, 2003: Snow process modeling in the North American Land Data Assimilation System (NLDAS): 1. Evaluation of model-simulated snow cover extent. J. Geophys. Res., 108, 8849, doi:10.1029/2002JD003274.

Skamarock, W. C., and J. B. Klemp, 2008: A time-split nonhydrostatic atmospheric model for weather research and forecasting applications. J. Comput. Phys., 227, 3465-3485, doi:10.1016/j.jcp.2007.01.037.

Swenson, S. C., and D. M. Lawrence, 2012: A new fractional snowcovered area parameterization for the Community Land Model and its effect on the surface energy balance.J. Geophys. Res., 117, D21107, doi:10.1029/2012JD018178.

Uboldi, F., C. Lussana, and M. Salvati, 2008: Three-dimensional spatial interpolation of surface meteorological observations from high-resolution local networks. Meteor. Appl., 15, 331345, doi:10.1002/met.76.

Winstral, A., and D. Marks, 2014: Long-term snow distribution observations in a mountain catchment: Assessing variability, time stability, and the representativeness of an index site. Water Resour. Res., 50, 293-305, doi:10.1002/2012WR013038. , K. Elder, and R. E. Davis, 2002: Spatial snow modeling of wind-redistributed snow using terrain-based parameters. J. Hydrometeor., 3, 524-538, doi:10.1175/ 1525-7541(2002)003<0524:SSMOWR >2.0.CO;2.

Wrzesien, M. L., T. M. Pavelsky, S. B. Kapnick, M. T. Durand, and T. H. Painter, 2015: Evaluation of snow cover fraction for regional climate simulations in the Sierra Nevada. Int. J. Climatol., 35, 2472-2484, doi:10.1002/joc.4136.

Zhang, T. J., 2005: Influence of the seasonal snow cover on the ground thermal regime: An overview. Rev. Geophys., 43, RG4002, doi:10.1029/2004RG000157. 